\title{
O USO DO RADAR DE PENETRAÇÃO NO SOLO NA INVESTIGAÇÃO DOS PROCESSOS DE TRANSFORMAÇÃO PEDOGEOMORFOLÓGICA
}

\author{
José Martin Ucha \\ Instituto Federal de Educação, Ciência e Tecnologia da Bahia - IF-BAHIA - Departamento de Ciências Aplicadas - \\ Rua Emídio dos Santos, s/n. - Salvador - Bahia - CEP 40301-015 - e-mail: ucha@ifba.edu.br
}

Geraldo da Silva Vilas Boas

Universidade Federal da Bahia - Instituto de Geociências, Departamento de Sedimentologia - UFBA/IGEO Av. Barão de Geremoabo, s/n - Salvador - Bahia - CEP 40170-290 - e-mail: geraldosvb@ufba.br

Gisele Mara Hadlich

Universidade Federal da Bahia - Instituto de Geociências, Departamento de Geoquímica - UFBA/IGEO Av. Barão de Geremoabo, s/n - Salvador - Bahia - CEP 40170-290 - e-mail: gisele@ ufba.br

\begin{abstract}
Resumo
Sobre os Tabuleiros Costeiros do Litoral Norte do estado da Bahia foi empregado o Radar de Penetração no Solo (Ground Penetrating Radar - GPR) em uma vertente com presença de depressões fechadas, formadas sobre o Grupo Barreiras, com o objetivo de avaliar as informações obtidas com essa técnica sobre as transformações pedogeomorfológicas existentes. Ao longo de duas topossequências, 25 perfis de solo foram abertos, descritos e classificados e foi aplicado o GPR. Verificou-se que os solos, a presença de depressões e o acúmulo de água estão intrinsecamente relacionados. A análise morfológica mostrou que os solos com duripã localizados fora da linha de ação do lençol freático suspenso estão em processo de transformação e que a degradação dos fragipãs e dos duripãs está relacionada com a ausência das condições de hidromorfia. O GPR possibilitou identificar os eventos inicializadores desses processos, relacionados com a presença de uma fratura e sua reativação. $\mathrm{O}$ artigo apresenta uma breve revisão sobre o uso do GPR, ainda muito pouco utilizado nos estudos de solos e geomorfológicos. Os resultados revelam que a investigação com o GPR não pode prescindir da análise integrada do solo e do relevo através dos sistemas convencionais, mas mostrou-se, sem dúvida, um poderoso auxiliar que permite observações que não seriam possíveis apenas com os procedimentos tradicionais.
\end{abstract}

Palavras-chave: Morfogênese, Grupo Barreiras, Pedotransformação, Podzolização.

\begin{abstract}
The contribution of the GPR in research on pedogeomorphological studies is presented. The GPR was used in a study along a slope with the presence of depressions, formed on the Barreiras Group in the northern coast of Bahia state. The GPR has been little used in studies of pedogeomorphological transformations, and the literature points to positive results and limitations of using this technique. In two toposequences, 25 soil profiles were opened, described, classified and applied the GPR. It was found that the soils, the presence of depression and the accumulation of water are intrinsically linked. Morphological analysis showed that soils with duripã located outside the line of action of ground water are suspended in the process of transformation and the degradation of fragipãs and duripãs is related to the absence of hydromorphic conditions. The GPR signalized the events of these processes, related to the presence of a fracture and its reactivation. Geophysical research can not do without the integrated analysis of the soil and relief through the conventional systems, but is undoubtedly a powerful aid that allows observations that would not be possible only with the traditional procedures.
\end{abstract}

Keywords: Morphogenesys, Barreiras Group, Pedotransformation, Podzolization 


\section{Introdução}

O Radar de Penetração no Solo - GPR é uma ferramenta cada vez mais empregada na prospecção geológica, na detecção de fraturas, de maciços rochosos, de espaços porosos em rochas carbonáticas, em estudos geotécnicos e como teste não destrutivos nas engenharias.

Apesar da ampla difusão nos últimos anos, o GPR ainda tem sido pouco utilizado nas pesquisas pedológicas e ainda menos na geomorfologia. Seu uso, entretanto, pode trazer interessantes contribuições para o entendimento das distribuições e transições entre os tipos de solos, principalmente entre solos que apresentam alto grau de diferenciação morfológica, auxiliando na identificação dos processos que atuaram na transformação do relevo.

Neste artigo são apresentados os princípios que envolvem a técnica e alguns artigos que tratam de aspectos de interesse da geomorfologia ou da pedologia. Será apresentado, então, um estudo de caso sobre a aplicação do GPR em uma topossequência no Litoral Norte do Estado da Bahia.

\section{Os Princípios de Funcionamento do GPR}

Os métodos de prospecção geofísica são utilizados para detectar e localizar corpos ou estruturas do subsolo de forma não destrutiva, possibilitando determinar sua dimensão e algumas propriedades físicas.

Dos vários métodos existentes na geofísica, dois têm sido mais utilizados na pesquisa geomorfológica e pedológica: os baseados na eletrorresistividade e aqueles baseados no eletromagnetismo, sendo este último base do GPR.

$\mathrm{O}$ termo radar significa radio detection and ranging. É um sistema que utiliza pulsos eletromagnéticos de curta duração, que teve seu uso desenvolvido na II Guerra Mundial. O método de investigação da subsuperfície através do uso de ondas eletromagnéticas data de 1950, porém apenas com a popularização dos computadores e a disseminação do cabo de fibra óptica, principalmente na década de noventa, tornou-se possível a utilização de equipamentos mais sofisticados para captar e tratar uma grande quantidade de informações em altas velocidades.

O funcionamento do GPR é baseado na produção de pulsos eletromagnéticos de alta frequência, variando entre 10 a $1000 \mathrm{MHz}$ em intervalos de tempo entre 10 e $100 \mathrm{~ns}$. Antenas emissoras transmitem os pulsos para o solo e sua resposta é captada por antenas receptoras. Os sinais refletidos são detectados, amplificados, digitalizados e estocados em computador (Figura 1).

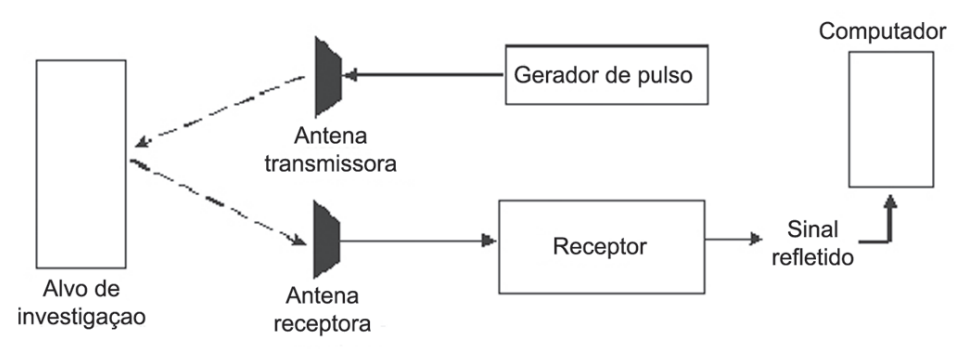

Figura 1 - Esquema de funcionamento do equipamento GPR. Adaptado de Herman (1997).

Ao atingir uma superfície com propriedades elétricas contrastantes, ocorre a reflexão do pulso, com parte da energia retornando para a superfície e outra se propagando no meio. A penetração do pulso do radar no solo é limitada principalmente pela atenuação, que por sua vez é governada pela condutividade do material. A atenuação é a energia dispendida pelo pulso ao mover as cargas elétricas (principalmente pela condutividade, mas também pela polarização) e é refletido pelos contrastes de condutividade e de permissividade elétricas (GREENHOUSE, 1998, p. 64).
A resolução vertical é limitada pelo comprimento de onda (I), que se relaciona com a frequência (f) e com a velocidade $(\mathbf{V})$ :

$$
\lambda=\mathbf{V} \mathbf{f}^{-}
$$

A resolução horizontal é determinada pelo padrão de radiação da antena, que funciona como um feixe de luz com um ângulo de abertura de 30 graus. A informação refletida pelo subsolo é uma média sobre a superfície refletora "iluminada" por esse feixe de ondas eletromagnéticas (GREENHOUSE, 1998, p. 65). 
O GPR detecta as mudanças abruptas das propriedades dielétricas (TOMER et al., 1996, p.121), de forma que as feições mais marcantes, como os fragipãs, duripãs, os horizontes coesos e as lamelas ou bandas ferruginosas, além de descontinuidades litológicas ou pedológicas, podem ser observadas ao longo dos perfis obtidos pelo radar.

Os resultados do GPR dependem da frequência utilizada e das condições do meio, principalmente da quantidade de água. Quanto mais úmido o solo, menor será a resolução. Isso afeta diretamente a análise das imagens quando as investigações são feitas em vários períodos do ano. $\mathrm{O}$ teor de água do solo e do subsolo pode gerar diferenças nas imagens e na sua interpretação. Respostas relativamente diferentes serão obtidas numa mesma área se estiver em período seco ou úmido, ou quando a água não penetrou o perfil completamente, ou então quando a parte superficial está seca e a umidade ainda é elevada nas camadas mais profundas. Solos arenosos e em condição insaturada são os melhores para a pesquisa com o GPR, que pode chegar a 50 metros de profundidade em casos onde o material apresenta condutividade elétrica menor que $1 \mathrm{mS} / \mathrm{m}$ (DAVIS, ANNAN, 1989, p. 532).

\section{Aplicação do GPR na Investigação Morfopedológica}

A maior parte do reduzido número de pesquisas aplicadas à investigação dos solos e/ou geomorfológica foi publicada a partir de 1990, apontando características positivas do uso do GPR, como a alta resolução na detecção de algumas feições, que vão desde poucos milímetros até vários metros de espessura.

Há avanços interessantes na divulgação do uso do GPR, como o trabalho de Doolitle et al. (2007), que confeccionaram um mapa para os EUA indicando aos potenciais usuários do GPR e as áreas com relativa aptidão para o seu emprego. O mapa é uma compilação de dados de solo, principalmente de atributos mineralógicos, tipos de argilas (atividade das argilas) e seu conteúdo nos solos, condutividade elétrica e RAS (razão de adsorção de sódio), e presença de carbonato e sulfato de cálcio.

Sem o objetivo específico da pesquisa em solos, Tomer et al. (1996, p. 125) utilizaram um solo arenoso com lamelas argilosas que produziram os refletores, visando adequar o uso da técnica a esse meio. Os autores mostraram que essas lamelas iluviais, mesmo aquelas com menos de um centímetro de espessura desenvolvidas em solos de origem eólica, foram detectadas pelo GPR. Essas lamelas são pedogenéticas, constituídas de argilas e óxidos de ferro e são fortes refletores por conter teores de água elevados em relação ao solo arenoso acima e abaixo da lamela, tendo sido bem representadas nos radargramas obtidos. A comparação entre as imagens do GPR e as trincheiras mostrou que há uma consistente relação entre a posição das lamelas no solo e os refletores captados pelo radar. Níveis secundários de lamelas são identificadas com dificuldade pelas imagens do GPR, por causa das reflexões geralmente menos contínuas que as registradas pelo nível de lamela superior. Tomer et al. (1996, p. 127) mostram que esse fato era esperado, uma vez que as ondas do radar sofrem atenuação com a profundidade e boa parte da energia emitida é perdida em reflexões e em interferências provenientes das camadas sobrepostas.

Analisando as barreiras costeiras dos Estados Unidos, Jol et al. (1996, p. 966) mostram que o GPR possui melhor resolução na identificação de detalhes da estratigrafia que outros métodos sísmicos, principalmente em lugares rasos, chegando a inferir as fácies sedimentares e as direções de paleodeposições.

Jol et al. (2003, p.176) analisaram diferentes frequências e energias de transmitância. Com a antena de 200 $\mathrm{MHz}$ foi atingida uma profundidade de 5-6 metros; com a antena de $25-50 \mathrm{MHz}$ foram alcançadas profundidades superiores a $10 \mathrm{~m}$, porém com baixa resolução; já com a antena de $100 \mathrm{MHz}$ atingiu-se a resolução aceitável com a profundidade de 7-8m, suficiente para identificar a base dos sedimentos pesquisados.

Outra aplicação do GPR que pode auxiliar as análises pedológicas e geomorfológicas foi identificada na investigação de contaminações no subsolo. Para conhecer e modelar os fluxos que agem no transporte de contaminantes, Collins et al. (1994, p. 11) pesquisaram uma área de carste onde as camadas de argila conduzem os fluxos contendo água e agrotóxicos para direção contrária a das dolinas, com resultado oposto do que a observação da topografia da superfície local sugeria. Compararam também o tempo gasto com a análise de 243 perfis com 3 metros de profundidade por pedólogos e pelo GPR, e registraram 120 horas de trabalho para os pedólogos, enquanto que com o radar foram gastas 12 horas para uma pesquisa mais abrangente, resultando numa considerável economia de recursos.

Em outro estudo específico, Freeland et al. (1998, p. 20) analisaram a aplicação do GPR na agricultura de precisão, para a produção de mapas tri-dimensionais com alta resolução dos solos, concluindo que o uso do GPR promoveu um eficiente, econômico e rápido meio de identificar, entre outros atributos, as áreas compactadas, a dimensão e a espessura dos horizontes do solo e a avaliação de suas propriedades hidrológicas.

Entre as limitações apontadas por Freeland et al. (1998, p. 26) estão a necessária familiaridade com as características físicas do local investigado, proporcionando uma calibração do equipamento com o desempenho dos diferentes modelos de antenas necessárias para os diferentes fins e a necessidade de treinamento avançado, pesquisa e desenvolvimento continuado do equipamento e da metodologia. 
Schrott e Sass (2008, p. 58) fizeram uma compilação sobre o uso de métodos geofísicos, apontando, entre as restrições ao uso do GPR na pesquisa geomorfológica, as diferentes reflexões produzidas por diferentes tamanhos dos grãos ou pelo teor de água existente no material pesquisado, impedindo uma análise correta do objeto de estudo. Propõem que a pesquisa geomorfológica deva ser feita com a utilização de mais de um método geofísico, associando o eletromagnético, a eletrorresistividade e a refração sísmica. Apontam também que medições em áreas florestais com o GPR são desaconselháveis pela contaminação de informações devido ao espalhamento das ondas pelas copas e troncos das árvores.
No Brasil, um trabalho pioneiro utilizando o GPR na pesquisa de solos (Ucha et al., 2002) abordou a importância dessa ferramenta, apontando que as feições mais perceptíveis foram os horizontes duripã e fragipã e que as informações geofísicas se mostraram adequadas para a pesquisa sobre a gênese e a pedotransformação ao longo da topossequência.

\section{Materiais e Métodos}

A pesquisa foi desenvolvida sobre um sítio denominado Rio Negro, localizado no Município de Entre Rios, que compõe a região econômica Litoral Norte do Estado da Bahia, distando 130km de Salvador (Figura 2).

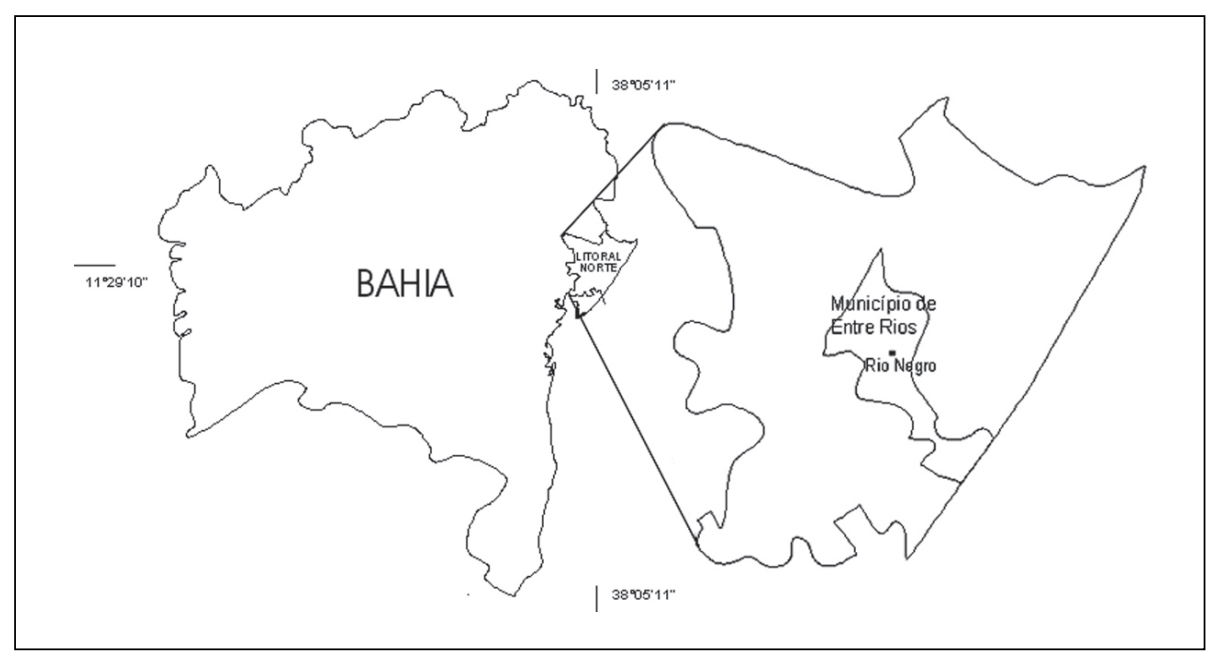

Figura 2 - Localização do sítio pesquisado.

O Grupo Barreiras é a única unidade litológica aflorante sobre os tabuleiros. São sedimentos terrígenos argilo-arenosos profundos, assentados sobre o embasamento cristalino. A idade do Grupo Barreiras vai do período Mioceno inferior/médio ao Plioceno (SUGUIO; NOGUEIRA, 1999; ARAI, 2006). A geomorfologia regional é caracterizada pelos Tabuleiros Costeiros, com topos planos e abaulados, extensos e com vales de vertentes abruptas.

O clima é do tipo tropical úmido. Segundo Köppen é classificado como Am, com precipitação no mês mais seco inferior a $60 \mathrm{~mm}$. Dados de precipitação local, com controle desde 1985, mostram que a média anual é da ordem de 1280 $\mathrm{mm}$.

A vegetação natural é formada por Floresta Ombrófila Densa (BRASIL, 1981, p. 423) e encontra-se bastante alterada pela ação antrópica. As áreas com Espodossolos hidromórficos que se encontram nas depres- sões, no interior dos tabuleiros, apresentam algumas espécies de savana e plantas típicas de restinga. Atualmente, a quase totalidade dos tabuleiros dos municípios do Litoral Norte do estado da Bahia está cultivada com eucaliptos e pinus e os vales são ocupados por pastagens e cultivos de subsistência diversos.

A vertente selecionada para este estudo possui aproximadamente $1900 \mathrm{~m}$ de extensão e declividade de $0,8 \%$, sobre a qual foram pesquisadas duas topossequências quase paralelas, nomeadas ERI e ERII (Figura 3). Ao longo da topossequência ERI foram abertos 17 perfis e em ERII foram estudados 8 perfis, todos com profundidade mínima de $200 \mathrm{~cm}$.

Os solos foram descritos e classificados segundo a Classificação Brasileira de Solos (EMBRAPA, 2006).

Tradagens foram efetuadas entre os perfis e no interior destes, buscando correlacionar os dados obtidos com o GPR com as características morfológicas. 
Para os levantamentos com o GPR foi utilizado o equipamento Geophysical Survey System - 2 (GSSI-2), com antena na frequência de $80 \mathrm{MHz}$. Optou-se por esta frequência devido à necessidade de se obter dados da maior profundidade possível, apesar da perda de resolução sobre as feições localizadas mais próximas à superfície, pois quanto menor a frequência empregada, maior a profundidade de investigação em detrimento de maior resolução superficial.

$\mathrm{O}$ arranjo utilizado foi o de aquisição por afastamento constante, que consiste na movimentação simultânea das antenas emissora e receptora, mantendo um afastamento constante entre elas - no caso, $150 \mathrm{~cm}$. O equipamento foi tracionado manualmente ao longo das duas topossequências.

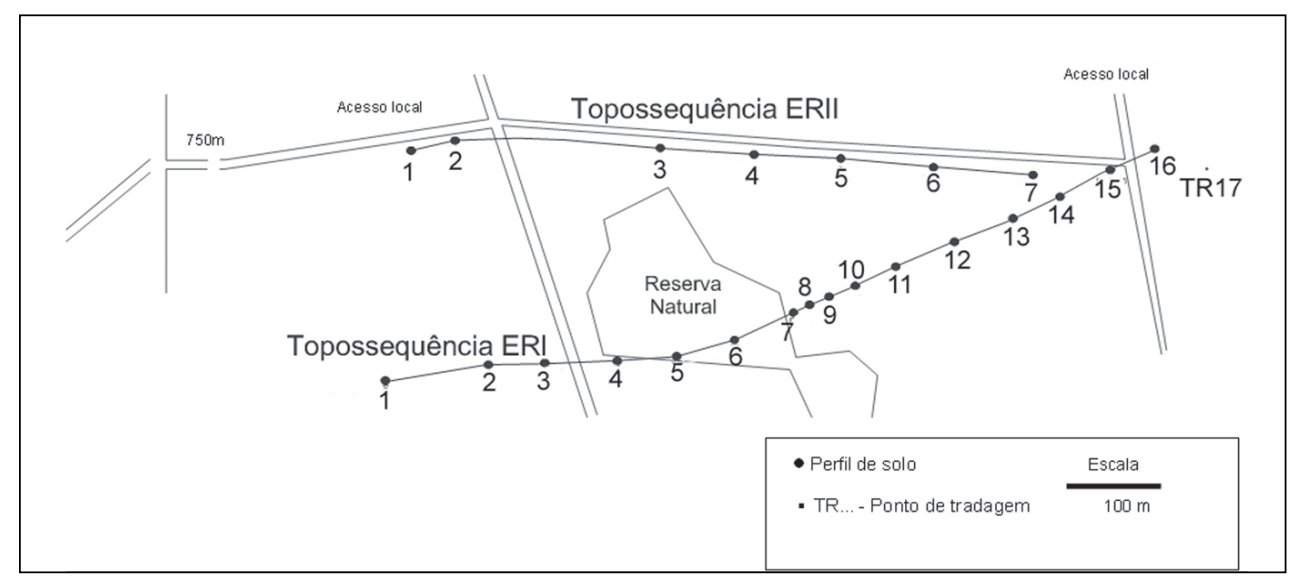

Figura 3 - Localização dos perfis nas topossequências ERI e ERII.

Na topossequência ERII os perfis foram abertos após a investigação com o GPR, que serviu de guia para a seleção dos pontos de localização dos perfis. Em ERI o procedimento foi o inverso: inicialmente foi feita a investigação dos solos e posteriormente a pesquisa com o GPR.

Os radargramas obtidos formaram um contínuo, com o final de cada imagem correspondendo ao início da imagem subsequente, propiciando uma visão completa da topossequência. Para efeito de armazenamento, cada arquivo correspondente aos trechos investigados foram limitados em aproximadamente $1,4 \mathrm{Mb}$, correspondente a uma extensão de 140 a $180 \mathrm{~m}$. As imagens foram processadas pelo software GRADIX e posteriormente editadas, estabelecendo a profundidade de $6,0 \mathrm{~m}$ como limite e unindo cada radargrama ao próximo, possibilitando a impressão de toda a sequência.

\section{Resultados}

Para a compreensão do conjunto dos processos que atuaram na evolução geomorfológica, são apresentadas as descrições morfológicas dos perfis de solos e suas posições ao longo da topossequência para, a seguir, relacionar com os resultados obtidos com o GPR, integrando as informações.

\section{Os solos e o relevo}

As áreas centrais das depressões possuem os solos com o mais avançado processo de podzolização, mantendo um lençol freático suspenso durante a maior parte do ano, mantido por um espesso horizonte duripã. Os processos de transformação desses solos podem ter início nas depressões (FILIZOLA et al., 2001, p. 961) e as depressões podem ter sua gênese determinada pela tectônica, como sugerido por Filizola e Boulet (1996, p. 84), Barbiero (1995, p. 37-39) e Carvalho (2000, p. 36). Para esses autores, eventos tectônicos e as fraturas decorrentes se constituíram nos fatores responsáveis pelo processo de abatimento da superfície que deram início à transformação dos solos e do relevo. Os mesmos processos, descritos através da investigação pedológica e geomorfológica e apoiados pelo uso do GPR, foram observados na presente pesquisa.

\section{Descrição morfológica da topossequência ER I}

O quadro 1 apresenta a descrição pedológica e morfológica da topossequência. 


\section{Quadro 1 - Principais atributos morfológicos da topossequência ERI.}

\begin{tabular}{|c|c|c|c|c|c|c|c|}
\hline \multirow[t]{2}{*}{ Local } & \multicolumn{7}{|c|}{ DEPRESSÃO 1} \\
\hline & borda & & & centro & & & borda \\
\hline Perfil & 1 & 2 & 3 & 5 & 8 & 9 & 10 \\
\hline Solo & $\begin{array}{l}\text { Argissolo Amarelo } \\
\text { Distrocoeso típico }\end{array}$ & $\begin{array}{l}\text { Argissolo Amarelo } \\
\text { Distrófico típico }\end{array}$ & $\begin{array}{c}\text { Espodossolo } \\
\text { Humilúvico Hidro- } \\
\text { hiperespesso } \\
\text { espessarênico }\end{array}$ & $\begin{array}{c}\text { Espodossolo } \\
\text { Humilúvico } \\
\text { Hidromórfico }\end{array}$ & $\begin{array}{c}\text { Espodossolo } \\
\text { Humilúvico } \\
\text { Hiperespesso }\end{array}$ & $\begin{array}{c}\text { Espodossolo } \\
\text { Humilúvico Órtico }\end{array}$ & $\begin{array}{l}\text { Argissolo Amarelo } \\
\text { Distrocoeso típico }\end{array}$ \\
\hline $\begin{array}{l}\text { Caract. } \\
\text { gerais }\end{array}$ & $\begin{array}{l}\text { - Bw expressivo entre } \\
\text { 48-220cm; } \\
\text { - bandas ferruginosas } \\
\text { em } 138 \mathrm{~cm} \text {; } \\
\text { - blocos de fragipã } \\
\text { (220-2400m) amarelo } \\
\text { avermelhado (7,5 YR } \\
\text { 6/8) em degradação }\end{array}$ & $\begin{array}{l}\text { - Bh }(270-280 \mathrm{~cm}) \\
\text { mistura-se com topo do } \\
\text { duripã; } \\
\text {-duripã }(280-350 \mathrm{~cm}+) \\
\text { em bloco maciço com } \\
\text { fraturas, mosqueado, } \\
\text { fundo bruno muito } \\
\text { claro-acinzentado }(10 \\
\text { YR } 7 / 3) \text { com manchas } \\
\text { amarelas (10 YR } 7 / 8) \\
\end{array}$ & $\begin{array}{l}\text { - hor. E (3-230cm; 4- } \\
\text { 180cm) } \\
\text { - Bh cinza muito escuro } \\
\text { (10 YR 3/1) misturado } \\
\text { com o duripã; } \\
\text {-3: duriapa mais } \\
\text { fraturado } \\
-4 \text { : duripã menos } \\
\text { fraturado }\end{array}$ & $\begin{array}{l}\text { - hor. E espesso (5: 20- } \\
170 \mathrm{~cm} \text { e 6: } 13-100 \mathrm{~cm}) \\
\text { branco (10 YR 8/2); } \\
\text { - presença de BH sobre } \\
\text { Bhm preto (10 YR } \\
\text { 2/11); } \\
\text { - duripã sustentando } \\
\text { lençol freático próximo } \\
\text { à superficie }\end{array}$ & $\begin{array}{l}\text { - hor. E 10-200cm; } \\
\text { - Bh bruno acinzentado } \\
\text { escuro (10 YR 4/3); } \\
\text { - duripã em degradacãa } \\
\text { Bunno escuro (10 YR } \\
3 / 3 \text { ) }\end{array}$ & \begin{tabular}{|l|} 
- hor. E com mais \\
matéria orgânica e \\
argila; \\
$-\mathrm{Bh}(15 \mathrm{~cm}$ espessura) \\
com muitas raizes \\
- duripã $(150-350+\mathrm{cm})$ \\
bastante fraturado
\end{tabular} & $\begin{array}{l}\text { - Bw expressivo de } 10 \\
\text { a } 200 \mathrm{~cm} ; \\
\text { - Banda ferruginosa } \\
\text { centimétrica em } \\
160 \mathrm{~cm} \text { e em } 240 \mathrm{~cm} \\
\text { - fragipã em } \\
\text { degradação entre 200- } \\
240 \mathrm{~cm}\end{array}$ \\
\hline
\end{tabular}

\begin{tabular}{|c|c|c|c|c|c|c|}
\hline \multirow[t]{2}{*}{ Local } & \multicolumn{3}{|c|}{ ENTRE DEPRESSÕES } & \multicolumn{3}{|c|}{ DEPRESSÃO 2} \\
\hline & & & & borda & & centro \\
\hline Perfil & 12 & 13 & 14 & 15 & 16 & $\operatorname{Tr} 17$ \\
\hline Solo & $\begin{array}{l}\text { Argissolos Amarelos Distrocoesos } \\
\text { latossólicos }\end{array}$ & $\begin{array}{c}\text { Argissolo } \\
\text { Acinzentado } \\
\text { Distrocoeso típico }\end{array}$ & $\begin{array}{c}\text { Argissolo } \\
\text { Distrocoeso típico }\end{array}$ & $\begin{array}{l}\text { Espodossolo } \\
\text { Humilúvico } \\
\text { Hiperespesso } \\
\text { espessarênico }\end{array}$ & \begin{tabular}{|l} 
Argissolo Amarelo \\
Distrocoeso \\
latossólico com \\
duripâ \\
\end{tabular} & $\begin{array}{c}\text { Espodossolo Hidro- } \\
\text { Hiperespesso } \\
\text { espessarênico }\end{array}$ \\
\hline $\begin{array}{l}\text { Caract. } \\
\text { gerais }\end{array}$ & $\begin{array}{l}\text {-presença de tipico hor. Bw amarelo avermelhado } \\
(7,5 \text { YR } 7 / 6) \text { com coeso entre } 50-125 \mathrm{~cm} \text { e entre } \\
125-160 \mathrm{~cm} ; \\
\text { - inexistência de fragipã e duripã }\end{array}$ & $\begin{array}{l}\text { - presença de típico } \\
\text { hor. Bw entre } 40- \\
160 \mathrm{~cm} ; \\
- \text { - Bh em } 160-170 \mathrm{~cm} \text {; } \\
\text { - duripã degradado } \\
\text { entre } 160-200 \mathrm{~cm}+\end{array}$ & $\begin{array}{l}\text { - presença de típico } \\
\text { hor. Bw entre 33- } \\
160 \mathrm{~cm} ; \\
\text { - duripã bruno } \\
\text { amarelado escuro (10 } \\
\text { YR 3/4) mais } \\
\text { degradado entre todos, } \\
\text { com intensa } \\
\text { penetração de matéria } \\
\text { orgânica }\end{array}$ & $\begin{array}{l}\text { - hor. E (130cm } \\
\text { espessura) bruno } \\
\text { amarelado claro (10 } \\
\text { YR 6/4); } \\
\text { - Bh incipiente; } \\
\text { - duripã em degradação } \\
\text { (>150cm) }\end{array}$ & $\begin{array}{l}\text { Entre } 65-170 \mathrm{~cm} \text { ocorre } \\
\text { hor. Bw bruno muito } \\
\text { claro acinzzentado ( } 10 \\
\text { YR 7/4), com restos de } \\
\text { duripã na massa } \\
\text { latossólica } \\
\text { - Bh incipiente; } \\
\text { - duripã em degradação } \\
\text { mais adiantada que em } \\
\text { ERI 15 }\end{array}$ & $\begin{array}{l}\text { - hor. E }(150 \mathrm{~cm} \\
\text { espessura); } \\
\text { - duripã sustentando } \\
\text { lençol freático }\end{array}$ \\
\hline
\end{tabular}

Obs.: As cores se referem a amostra úmida.

Observa-se que o centro da depressão 1 abrange os perfis 5 e 6 . Em ERI 6 o horizonte E possui menor espessura e o duripã e o lençol freático estão mais próximos da superfície. Os perfis apresentam o horizonte E constituído por areias muito lavadas, brancas, onde a podzolização atingiu o grau máximo. O horizonte $\mathrm{Bh}$, com $10 \mathrm{~cm}$ em média, está assentado sobre um ortstein - Bhm - horizonte iluvial formado por matéria orgânica e ferro, muito escuro e endurecido, em contato com a água durante quase todo o ano. $\mathrm{O}$ ortstein varia entre 10 e $20 \mathrm{~cm}$ e transiciona diretamente para o duripã com uma pequena diferenciação resultante do acúmulo de MO, que não existe no duripã. Várias campanhas de campo mostraram que, mesmo durante os meses de menor precipitação, o perfil ERI 6 se mostrava muito úmido em profundidade e, durante o período das chuvas, se apresentava com o nível do lençol sempre elevado.

A montante da depressão, o ponto ERI 4 ainda sofre influência da flutuação do lençol freático, o que lhe confere um estado de degradação do duripã menor do que o observado no perfil ERI 3 que não sustenta o lençol freático e as raízes descem pelo horizonte $\mathrm{E}$, surgindo em profusão no $\mathrm{Bh}$ e no topo escurecido do próprio duripã, penetrando por entre as fendas e as fraturas existentes.

À exceção dos duripãs dos perfis ERI 5 e ERI 6, o perfil ERI 2 possui o duripã mais preservado de toda a topossequência, notadamente por não acumular água sobre este horizonte devido a sua posição no relevo. Apresenta fraturas ao longo do bloco maciço e a mistura da matéria orgânica do horizonte $\mathrm{Bh}$ com partes do topo do duripã altera a cor esbranquiçada deste último para uma cor mais escura e torna o horizonte mais friável e com grande quantidade de raízes, que não são observadas nos duripãs não degradados ou funcionais (ERI 5 e ERI 6).

Na parte mais elevada da topossequência, em ERI 1, a Classificação Brasileira de Solos (EMBRAPA, 2006) remete o solo para a classe dos Argissolos, porém não há processo de perda e transporte a partir da superfície ou mesmo lateralmente e o solum é, tipicamente, um latossolo, mas com blocos de fragipã associados ao processo de transformação podzólica lateral relacionado com a flutuação do lençol freático, que foi delimitado pelo nível da água que atingiu o centro da depressão como uma língua que penetrou subsuperficialmente, a partir da depressão. Há acumulações de ferro (bandas ou lamelas ferruginosas) em forma de pequenas porções descontínuas alinhadas ou em forma de linha mais contínua. Há degradação do fragipã e das bandas ferruginosas que se apresentam macias e friáveis, com evidências de liberação do ferro, e o fragipã aparece com raízes se desenvolvendo em meio aos blocos e entre partes do horizonte endurecido de cor mais clara que a do solo circundante.

Para jusante da primeira depressão, os perfis ERI 7 e ERI 8 apresentam muitas raízes se desenvolvendo no horizonte Bh e duripã em degradação. O perfil ERI 9 apresenta horizonte duripã a partir de $150 \mathrm{~cm}$ de profundidade com mais de $200 \mathrm{~cm}$ de espessura, extremamente fraturado, não acumulando água mesmo durante os episódios de chuvas intensas. As raízes dos eucaliptos penetram por entre as fraturas. Os horizontes eluviais também apresentam características 
diferenciadas dos perfis ERI 3 ao ERI 8, com maior quantidade de matéria orgânica e maior quantidade de argila.

O perfil ERI 10 apresenta características latossólicas. Bandas ferruginosas a partir dos $100 \mathrm{~cm}$ aparecem com aspecto de degradação. Blocos de fragipã centimétricos soltos na massa latossólica são observados a partir de $160 \mathrm{~cm}$. Os únicos perfis que possuem fragipã, o ERI 1 e o ERI 10, apresentam em comum a posição que ocupam na vertente em relação aos perfis que possuem o horizonte duripã: ambos estão localizados na borda da primeira depressão.

No fundo dos perfis ERI 11 e 12 foram efetuadas tradagens atingindo a profundidade de $400 \mathrm{~cm}$, sendo encontrado apenas um material argiloso amarelo avermelhado, com uma banda ferruginosa em $300 \mathrm{~cm}$ (ERI 11), friável e sem material esbranquiçado.

O perfil ERI 13 situa-se na transição entre os Latossolos Amarelos de montante e os Espodossolos de jusante. É um perfil complexo, com horizonte coeso sobre um horizonte latossólico que grada para um horizonte Bh que está assentado sobre um duripã em degradação. O duripã está fraturado e as raízes invadem os blocos soltos.

O perfil ERI 14 também apresenta características de um perfil intermediário. É o perfil que apresenta o mais evoluído estádio de degradação do duripã, restando pou- cos blocos de maior diâmetro. A matéria orgânica penetra o material antes endurecido, tornando-o friável e mais escurecido que o material circundante, o que faz com que os fragmentos de duripã se destaquem perfeitamente do restante do solo.

O perfil ERI 15 localiza-se próximo da área rebaixada da segunda depressão. O duripã aparece degradado, com blocos entremeados por material friável e escurecido pela matéria orgânica. O perfil ERI 16 é um perfil de transição, com características intermediárias entre o argissolo, o latossolo e o espodossolo, com duripã bastante degradado com porções arredondadas soltas em meio à massa latossólica, indicando a transformação do duripã que se friabiliza como um latossolo, inclusive com estrutura granular.

O centro da segunda depressão foi observado através do ponto de tradagem TrERI 17 e, durante o período das chuvas, apresentou o lençol em $140 \mathrm{~cm}$ de profundidade.

\section{Descrição morfológica da topossequência ER II}

A análise dos perfis da topossequência ERII (Quadro 2) mostra os mesmos domínios existentes na topossequência ERI, porém localizados na área mais externa da primeira depressão.

\section{Quadro 2 - Principais atributos morfológicos da topossequência ERII.}

\begin{tabular}{|c|c|c|c|c|c|c|}
\hline \multirow{3}{*}{$\begin{array}{l}\text { Local } \\
\text { Perfil }\end{array}$} & \multicolumn{4}{|c|}{ DEPRESSÃO 1} & \multirow{2}{*}{$\begin{array}{c}\text { ENTRE } \\
\text { DEPRESSÕES }\end{array}$} & \multirow{3}{*}{$\begin{array}{c}\text { DEPRESSÃO } 2 \\
\text { borda } \\
8\end{array}$} \\
\hline & \multicolumn{2}{|c|}{ borda } & \multirow{2}{*}{$\frac{\text { centro }}{4}$} & \multirow{2}{*}{$\frac{\text { borda }}{5}$} & & \\
\hline & 1 & 3 & & & 7 & \\
\hline Solo & $\begin{array}{c}\text { Argissolo Amarelo } \\
\text { Distrocoeso } \\
\text { latossólico }\end{array}$ & $\begin{array}{c}\text { Argissolo Amarelo } \\
\text { Distrocoeso } \\
\text { fragipânico }\end{array}$ & $\begin{array}{c}\text { Espodossolo } \\
\text { Humilúvico } \\
\text { Hiperespesso } \\
\text { espessarênico }\end{array}$ & $\begin{array}{c}\text { Argissolo } \\
\text { Acinzentado } \\
\text { Distrófico dúrico }\end{array}$ & $\begin{array}{c}\text { Latossolos Amarelos } \\
\text { Distrocoesos }\end{array}$ & $\begin{array}{c}\text { Espodossolo } \\
\text { Humilúvico } \\
\text { Hiperespesso } \\
\text { arênico }\end{array}$ \\
\hline $\begin{array}{c}\text { Caract. } \\
\text { gerais }\end{array}$ & $\begin{array}{l}\text { - Bw expressivo entre } \\
150-210 \mathrm{~cm}^{+} \\
\text {- bandas ferruginosas } \\
\text { difusas } \mathrm{em} 170 \mathrm{~cm}\end{array}$ & $\begin{array}{l}\text { - sob a banda } \\
\text { ferruginosa em } 170 \\
\text { cm;ocorre um material } \\
\text { esbranquiçado difuso, } \\
\text { sobre a banda aparece } \\
\text { um fragipã pouco } \\
\text { evoluido, que desce em } \\
\text { algumas partes desde } \\
\text { os } 120 \mathrm{~cm}, \text { formando } \\
\text { grandes massas com } \\
\text { caráter frágico, em } \\
\text { degradação }\end{array}$ & $\begin{array}{l}\text { - hor. E espesso sem } \\
\text { outros horizontes } \\
\text { definidos; } \\
\text { - areia com MO bruno } \\
(10 \text { YR } 5 / 3)\end{array}$ & $\begin{array}{l}\text { - duripã em degradação } \\
\text { mosqueado, bruno } \\
\text { avermelhado escuro } \\
\text { ( } 2,5 \text { YR } 3 / 4 \text {, úmido), } \\
\text { bruno forte (7,5 YR } \\
5 / 8 \text { ) partir de } 100 \mathrm{~cm}\end{array}$ & $\begin{array}{l}\text { - amarelo brunado ( } 10 \\
\text { YR } 6 / 6 \text { ) com coeso } \\
\text { entre } 20-80 \mathrm{~cm} \text { e } 80 \text { - } \\
170 \mathrm{~cm}\end{array}$ & $\begin{array}{l}\text { - hor. E entre } 10- \\
110 \mathrm{~cm}, \text { bruno muito } \\
\text { claro(10 YR } 7 / 3) ; \\
\text { - duripã em } \\
\text { degradação a partir de } \\
115 \mathrm{~cm}\end{array}$ \\
\hline
\end{tabular}

As cores se referem à amostra úmida.

Os perfis ERII 1 e ERII 2 estão situados no topo da depressão. Não possuem horizontes endurecidos, no entanto, o perfil ERII 2 apresenta bandas ferruginosas friáveis em $170 \mathrm{~cm}$, com manchas avermelhadas distintas, sem indícios de formação de fragipã.

O perfil ERII 3 possui banda ferruginosa em $180 \mathrm{~cm}$. Acima da banda aparecem blocos de material claro pouco endurecidos, como um fragipã que não se formou completamente, e abaixo da banda ocorrem porções esbranquiçadas, difusas, sem uma cimentação aparente. Há raízes entre as porções esbranquiçadas.
O perfil ERII 4 está localizado na área mais próxima do centro da primeira depressão. Apresenta como característica peculiar a inexistência de horizonte endurecido e até a profundidade de $450 \mathrm{~cm}$ não foi encontrado nada além de sedimento arenoso sem qualquer estrutura.

A jusante, o perfil ERII 5 apresenta horizonte duripã em degradação a partir dos $100 \mathrm{~cm}$. Perfil semelhante ao ERI 9.

Os perfis ERII 6 e ERII 7 são Latossolos argilosos sem indícios de podzolização. São análogos aos perfis ERI 11 e 
ERI 12, porém com as características latossólicas mais preservadas.

O perfil ERII 8 é um Espodossolo com duripã em degradação a partir de $115 \mathrm{~cm}$, com muitas raízes se desenvolvendo sobre e por entre os blocos de duripã preenchidos pelo Bh. Ocupa a mesma área do perfil ERI 13, porém com o duripã relativamente mais preservado.

\section{Análise das feições morfopedológicas obtidas pelo GPR}

As principais feições observadas através do GPR foram os horizontes duripã e fragipã, por se constituírem em ótimos refletores das ondas eletromagnéticas.

As ondas passam através do material existente entre a superfície e o contato com o duripã sem mostrar qualquer impedimento à sua passagem, e as linhas paralelas representadas no radargrama sobre essa zona nada mais são do que o efeito do espalhamento das ondas nas proximidades das antenas pelas árvores do reflorestamento de eucalipto, gerando as linhas paralelas, que são interpretadas como ruídos sem qualquer relação com o material existente.

Embora esse fenômeno seja comum a todos os radargramas e que esse efeito causa a perda de informações sobre os primeiros centímetros do solo, em nada interferiu nas respostas subsuperficiais, indicando que as observações de Schrott e Sass (2008, p. 58) sobre a não conveniência do uso do GPR em áreas florestais devem ser tomadas com reservas.

Os radargramas não permitem identificar as bandas ferruginosas ou estabelecer um padrão específico para o fragipã, que aparecem geralmente próximos, mas a morfologia mostra que este horizonte está presente na área onde o refletor se torna gradualmente descontínuo, ou seja, os fragipãs são encontrados somente nas frentes de transformação, entre o duripã e os solos não podzolizados, indicando uma sequência evolutiva que principia com as bandas ferruginosas, avança para o fragipã e tem seu máximo com o duripã, fato também descrito por Filizola et al. (2001) para as depressões dos tabuleiros nos estados de Alagoas e Pernambuco.

\section{Radargrama da topossequência ERI}

A figura 4 mostra a integração dos atributos pedológicos ao radargrama da topossequência ERI. O ponto zero mostra um solo homogêneo sem a presença de refletores fortes, porém, observa-se que, desde o ponto zero, na profundidade de 3 metros, há porções que apresentam refletores fracos e espaçados, que são os fragipãs que vão se tornando mais fortes e, na distância de $106 \mathrm{~m}$, adquirem a feição dos duripãs espessos.
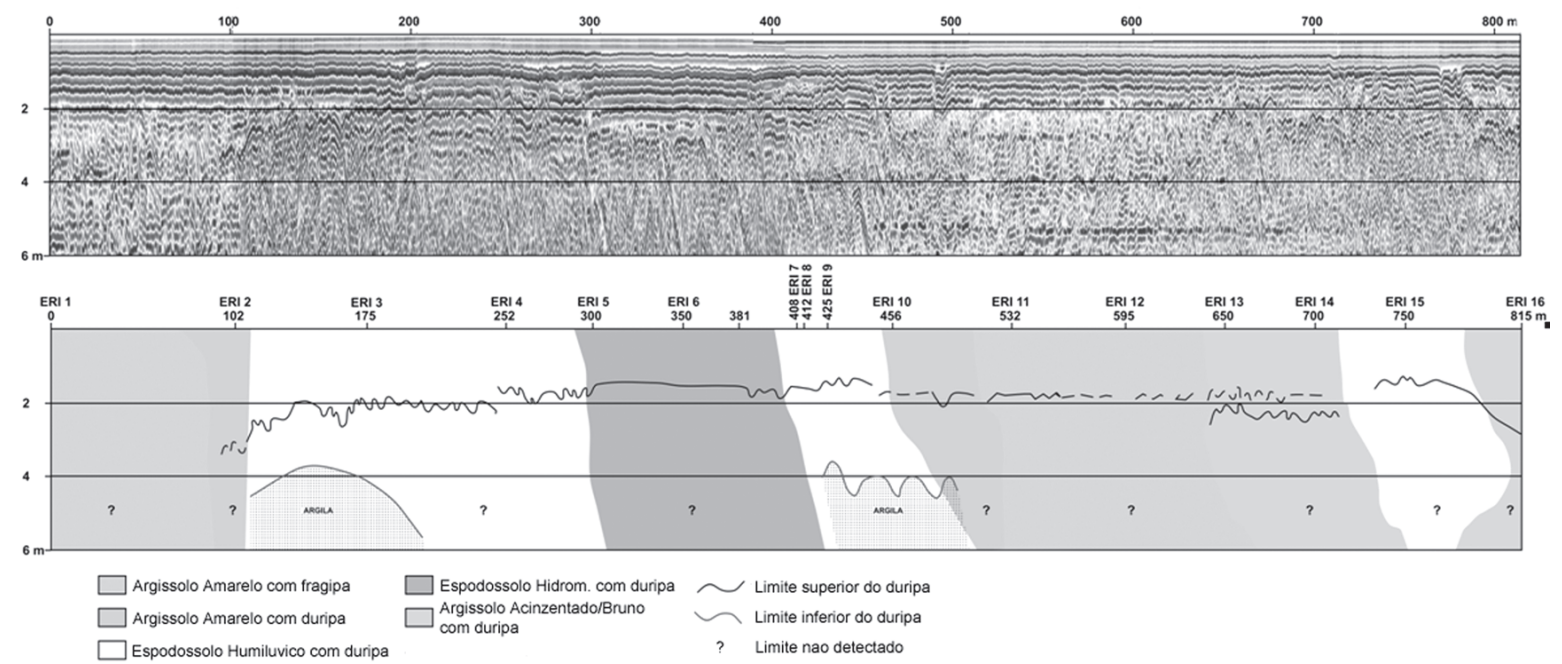

Figura 4 - Interpretação dos atributos pedológicos e geofísicos da topossequência ERI.

O conjunto formado pelos blocos endurecidos permeados por fendas preenchidas por material friável apresenta um comportamento de reflexão dos pulsos eletromagnéticos que foi observado em todos os duripãs em degradação nas duas topossequências (ERI e ERII).

A partir dos $106 \mathrm{~m}$ do radargrama ERI, os refletores mostram pontos de inflexão formando V's invertidos que identificam os topos dos blocos do duripã em degradação, mas não definem com clareza o seu limite inferior em razão da difração dos sinais que pode ser resumida como a reflexão de uma parte das ondas emitidas pelos topos dos blocos de duripã; no entanto, as ondas ultrapassam com reduzida atenuação o material friável e as fendas entre esses blocos em degradação, conforme observado na comparação com os dados morfológicos. Isso gera uma mistura de sinais e compromete a identificação do limite inferior do horizonte duripã. 
Para confirmar a espessura do duripã foi efetuada uma tradagem na topossequência ERII, na distância de $165 \mathrm{~m}$, que revelou que os horizontes arenosos (A e E) somam aproximadamente $3,0 \mathrm{~m}$ de profundidade e que o duripã surge em 3,0m e desaparece em 5,5m. A partir desse nível ocorre um material muito argiloso de coloração rosada. Portanto, o GPR não definiu com nitidez o limite inferior do duripã.

O perfil ERI 2 está localizado na distância de 102m, sobre o refletor forte que surge de forma contínua em $100 \mathrm{~m}$. Esse refletor é interrompido em $113 \mathrm{~m}$ e reaparece em $130 \mathrm{~m}$. O perfil ERI 3 está localizado em $175 \mathrm{~m}$. Observa-se que o nível de duripã torna-se mais superficial na medida em que se avança no radargrama, passando pelo perfil ERI $4 \mathrm{em} 252 \mathrm{~m}$ e pelo ERI $5 \mathrm{em} 300 \mathrm{~m}$, até atingir a distância de $347 \mathrm{~m}$. Mais profundo em montante, o duripã está mais superficial na parte mais central da primeira depressão, com uma diferença da ordem de 1,2m entre esses dois pontos. Na descrição dos perfis pode-se observar que o duripã do perfil ERI 2 aparece em 2,8-3,0m, enquanto que no perfil ERI $6(350 \mathrm{~m})$ aparece em $1,3 \mathrm{~m}$.

Como os radargramas não foram corrigidos em relação à topografia do terreno, o que aparece a montante como mais profundo está, na verdade, mais elevado. A diferença entre as cotas topográficas dos duripãs dos perfis ERI $2 \mathrm{e}$ ERI 6 é de $0,5 \mathrm{~m}$. No radargrama o topo do duripã do ERI 6 aparece em 1,6m de profundidade e o topo do duripã do ER 2 aparece em 2,7m. Esses resultados, depois de corrigidos em relação ao desnível topográfico, são compatíveis aos obtidos com a descrição morfológica.

Observa-se também que, desde a distância de $272 \mathrm{~m}$ o refletor é mais suave e contínuo, mostrando a área onde o lençol freático aparece sobre o duripã funcional. Essa feição desaparece após os $380 \mathrm{~m}$, onde as quebras do refletor ressurgem, indicando o domínio do duripã fraturado e em degradação.

O perfil ERI 7 está localizado em 400m, o ERI 8 em $408 \mathrm{~m}$ e o ERI $9 \mathrm{em} \mathrm{425m}$. Em 450m existe uma mudança nos padrões de reflexão mostrando o fim do duripã, delimitando o final do domínio do processo de podzolização de jusante, confirmando a sequência duripã - fragipã. O perfil ERI 10, localizado em $456 \mathrm{~m}$, está sobre a porção final do avanço da transformação, mostrando o fragipã em degradação que passa a dominar o radargrama a partir dos $460 \mathrm{~m}$, onde não são mais notados os refletores fortes, mostrando um material aparentemente homogêneo em profundidade.

Os perfis ERI 11 e ERI 12 em 532 e 595m mostram o domínio dos Argissolos Amarelos latossólicos, que representam o hiato existente entre as duas depressões e seus respectivos sistemas de transformação pedológica.

Em 640m uma tradagem revelou a existência de fragipã muito degradado, seguindo com a repetição da sequência, com a volta do duripã representado pelo refletor forte em $650 \mathrm{~m}$, descontínuo em função do avançado estádio de degradação desse duripã que, paulatinamente, se torna mais espesso, passando pelo perfil ERI $14 \mathrm{em} 700 \mathrm{~m}$, tornando a reaparecer de forma mais expressiva a partir dos $725 \mathrm{~m}$, seguindo até os $785 \mathrm{~m}$. O perfil ERI 15 está localizado em 750m, sobre um duripã espesso e o mais superficial entre os duripãs da segunda depressão. Esse domínio segue até os 795m, a partir de onde surge um material que mostra características semelhantes a do Argissolo Amarelo latossólico de montante (ERI 11 e ERI12), juntamente com horizonte duripã que mergulha para a profundidade superior aos $2 \mathrm{~m}$. O perfil ERI 16 está localizado exatamente no final do radargrama, em $815 \mathrm{~m}$.

\section{Radargrama da topossequência ERII}

Observa-se na figura 5 que entre a distância 0 e $50 \mathrm{~m}$ existem refletores fracos que estão relacionados com as bandas ferruginosas abaixo dos $200 \mathrm{~cm}$, que se tornam menos expressivas quanto mais à montante.

A presença do duripã é bem marcada entre 50 e $80 \mathrm{~m}$ com um forte refletor. O perfil ERII 2 é um Argissolo Amarelo Distrocoeso latossólico, com banda ferruginosa difusa em $170 \mathrm{~cm}$. O perfil ERII 3 mostra a presença do fragipã pouco evoluído sobre a banda ferruginosa. Esses perfis estão localizados em 14 e 53m, respectivamente. Portanto, o início do horizonte cimentado, representado pelo fragipã, é nítido, e sua passagem para o duripã ocorre como um contínuo, sem nenhuma evidência de fases que indiquem alguma separação entre fragipã e duripã.

Como pode ser observado nas transições Argissolo Amarelo latossólico/Espodossolo com duripã nas distâncias $385 \mathrm{~m}, 433 \mathrm{~m}, 460 \mathrm{~m}$ e $613 \mathrm{~m}$, os limites parecem repetir a sequência duripã/fragipã. Essa sequência foi confirmada pelo perfil ERII 3 e pelas tradagens realizadas sobre esses pontos, evidenciando que o fragipã está sempre presente na frente de formação do duripã.

O perfil ERII 4 é um Espodossolo hiperespesso em $304 \mathrm{~m}$, sem presença de horizonte cimentado. Esse Espodossolo surge no meio de Espodossolos com duripãs espessos e a tradagem no fundo do perfil não revelou qualquer indício de cimentação. A área de domínio desse perfil se estende por pouco mais de $15 \mathrm{~m}$, mostrando que se trata de uma interessante anomalia onde o duripã é abruptamente interrompido e o perfil é completamente arenoso até a profundidade superior a $4 \mathrm{~m}$. Essa anomalia foi interpretada como evidência da fratura que corta a primeira depressão no sentido longitudinal em perfeito alinhamento com os perfis ERI 7 e ERI 8, que também apresentam os mesmos indícios de fratura do corpo do duripã devido ao movimento tectônico. 

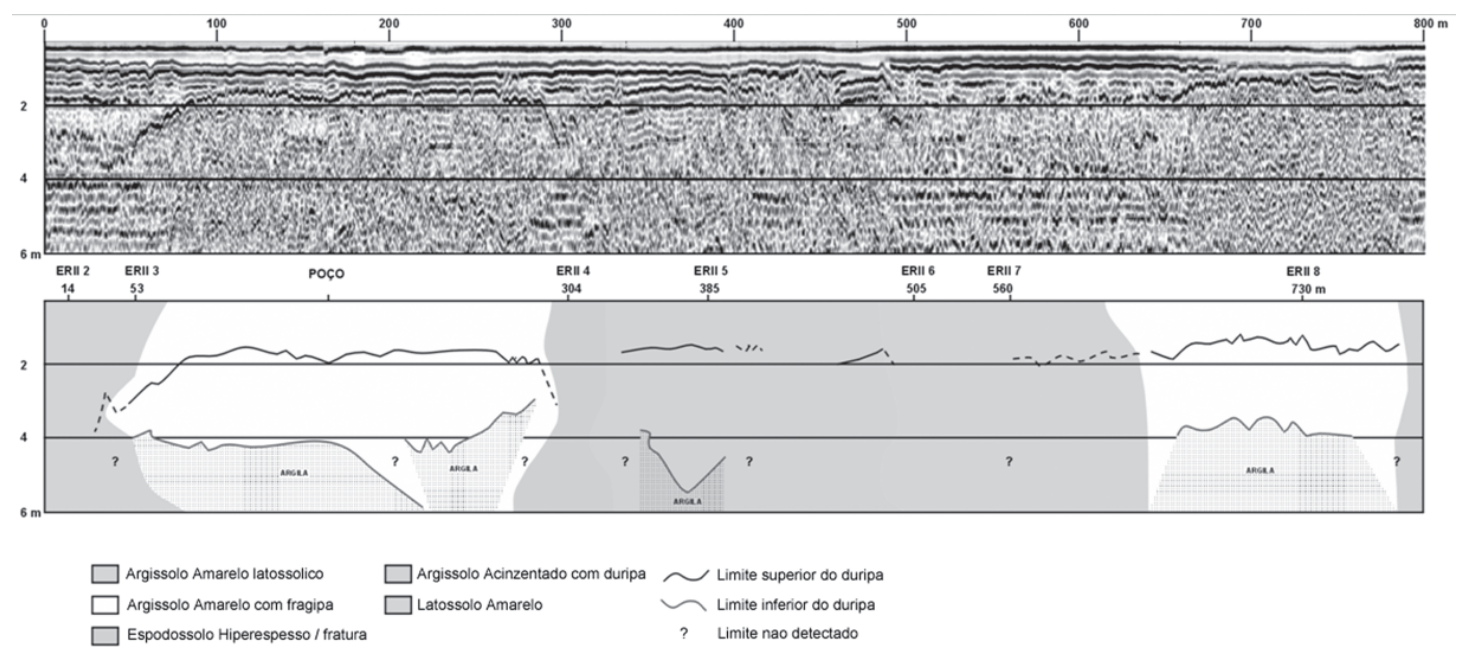

Figura 5 - Interpretação dos atributos pedológicos e geofísicos da topossequência ERII.

O perfil ERII 5 está localizado na distância $385 \mathrm{~m}$, um Argissolo Acinzentado com duripã, com o mesmo padrão do domínio dos solos com duripã em degradação ao longo de toda a topossequência. $\mathrm{O}$ sistema complexo de transições laterais apresentado entre as distâncias 295 - 440m está relacionado com o fato de que essa topossequência cortou uma parte da borda norte da primeira depressão, mostrando áreas latossólicas em meio da frente de transformação podzólica. Como a podzolização não avança de forma homogênea em todos os sentidos das bordas, partes mais preservadas e outras mais intensamente podzolizadas surgem lado a lado, porém estão relacionadas geneticamente com o centro da depressão.

Os perfis ERII 6 e ERII 7, localizados em 505 e 560 $\mathrm{m}$, mostram o domínio dos Latossolos Amarelos Distrocoesos. O padrão de reflexão é típico dos solos sem duripã. A transição encontrada no final do Latossolo em 640m é parecida com a existente no início do radargrama, quando surge o primeiro duripã. Pode-se observar que o refletor forte surge na profundidade de $3,0 \mathrm{~m}$, alterando, a partir desse ponto, todo o padrão até a distância $784 \mathrm{~m}$, onde volta a mostrar um padrão de reflexão típico dos latossolos.

A nitidez dessa transição, já no domínio da segunda depressão (a partir de $613 \mathrm{~m}$ ), é menor que a encontrada na frente de transformação da primeira depressão $(60 \mathrm{~m})$, provavelmente devido ao fato de que a segunda depressão apresenta um estádio de degradação dos horizontes duripã mais avançado que o encontrado na primeira depressão.

O final do radargrama mostra o perfil ERII 8 localizado em $730 \mathrm{~m}$, dentro do domínio dos Espodossolos Hiperespessos com duripã.

\section{Análise integrada dos radargramas ERI e ERII}

As feições observadas nos dois radargramas são confirmadas pelos perfis e tradagens. Os domínios dos duripãs e dos solos sem horizontes endurecidos evidenciam transições rápidas, onde o duripã se mostra cada vez mais delgado, até desaparecer numa área onde pequenas porções endurecidas indicam a transição duripã-fragipã. A sequência indica que o desenvolvimento não se dá de forma homogênea, ao contrário, ele vai acompanhando as bandas ferruginosas, a formação dos fragipãs e os impedimentos à drenagem da água, associados ao nível do lençol freático que é encontrado no centro da depressão.

No processo de degradação do duripã observa-se que a friabilização do solo é sempre acompanhada pelas raízes das plantas, separando blocos, abrindo e ampliando fendas no interior do duripã.

Como os processos atuais que predominam sobre as topossequências ERI e ERII são de degradação dos horizontes endurecidos, a transição entre os domínios dos duripãs e dos fragipãs, estes últimos em mais avançado estádio de degradação, não foram identificados com maior resolução. Apesar de não haver uma feição específica para o fragipã, foi provado que ele está sempre localizado nas partes distais das frentes de transformação, associado ao início do duripã e acompanhando as bandas ferruginosas. Nos radargramas essas zonas são representadas pela quebra de continuidade do refletor forte.

O rebaixamento abrupto do duripã sob os perfis ERI 7 e ERI 8 e o seu alinhamento com a anomalia existente sob o perfil ERII 4 mostra que a fratura que rompeu os duripãs e rebaixou o nível do lençol freático, possui direção NW-SE, expondo os duripãs e fragipãs não atingidos pela hidromorfia aos processos de degradação, que provavelmente ocupa a mesma posição do evento tectônico que originou a depres- 
são que, por sua vez, deu origem aos primeiros fragipãs e duripãs. Esta direção é corroborada pelas observações de Gomes (1998 p.82) e Misi e Silva (1996, p.101), que relacionaram diversas mineralizações com os fraturamentos nesse mesmo sentido, dentro das mega-estruturas que acompanham a estruturação geral do Cráton do São Francisco.

\section{Conclusões}

O GPR mostrou-se uma ferramenta de grande utilidade para a investigação dos processos de transformação dos solos e do relevo, pois propiciou a análise da distribuição dos horizontes duripã e fragipã ao longo da topossequência e mostrou as evidências de eventos tectônicos e sua relação com o processo evolutivo da vertente.

A investigação geofísica não pode prescindir da análise integrada do solo e do relevo através dos sistemas convencionais, mas é, sem dúvida, um poderoso auxiliar que permite observações que não seriam possíveis apenas com os procedimentos tradicionais.

Enquanto a análise morfológica permite afirmar que os solos com duripã localizados fora da linha de ação do lençol freático suspenso estão em processo de transformação e que a degradação dos fragipãs e dos duripãs está relacionada com a inexistência das condições de hidromorfia, o GPR possibilitou localizar os eventos causadores desses processos que poderiam passar despercebidos com a utilização dos métodos usuais em estudos dos solos e da geomorfologia, especificamente a existência de uma fratura, que iniciou os processos de abatimento do relevo e a podzolização dos solos e a posterior reativação dessa fratura, responsável pelo rebaixamento do lençol e que vem agindo na sua degradação atual.

\section{Referências Bibliográficas}

ARAI, M. A Grande Elevação eustática do Mioceno e sua influência na origem do Grupo Barreiras. Geol. USP Sér. Cient., São Paulo, v.6, n2, p. 1-6, 2006.

BARBIERO, L. Aspects morphologiques du pasage latosolplanosol, gênese et evolution actuelles: Itaberaba - Bahia, Brésil. Paris: Ministére des Affectes Etranger. 62 p., il, 1995.

BRASIL. Ministério das Minas e Energia. Secretaria Geral. Folha SD 24 Salvador: geologia, geomorfologia, pedologia, vegetação, uso potencial da terra. Rio de Janeiro. v. 24, 620 p. il. 1981.

CARVALHO, C. C. N. Gênese e evolução dos Latossolos Amarelos no Reconcâvo Baiano. Dissertação (Mestrado em Geoquímica e Meio Ambiente) - Instituto de Geociências,
Universidade Federal da Bahia, Salvador. Orientador: Prof. Dr. Lucedino Paixão Ribeiro, 2000.

COLLINS, M.; CUM, M.; HANNINEN, P. Using groundpenetrating radar to investigate a subsurface karst landscaspe in north-central Florida. Geoderma, [Amsterdam], n. 61, p. 1-15, 1994.

DAVIS, J. L.; ANNAN, A. P. Ground-penetrating radar for high-resolution mapping of soil and rock stratigraphy. Geophysical Prospecting, [S.1.], n. 37, p. 531-551, 1989.

DOOLITTLE, J.A.; MINZENMAYER, O. F.E.; WALTMAN, S.W.; BENHAM, E.C.; TUTTLE, J.W.; PEASLEE, S.D. Ground-penetrating radar soil suitability map of theconterminous United States. Geoderma, vol. 141, p. 416421, 2007.

EMBRAPA. Sistema brasileiro de classificação de solos. Brasília: EMBRAPA. 2. ed. 306 p., il, 2006.

FILIZOLA, H. F.; BOULET, R. Evolution and opening of closed depressions developed in a quartz-kaolinitic sedimentare substratum at Taubaté basin (São Paulo - Brazil), and analogy to the slope evolution. Geomorphology: An International Journal of Pure and Applied Geomorphology, Liverpool, n.16, p.77-86, 1996.

FILIZOLA, H. F.; LAMOTTE, M.; FRITSCH, E.; BOULET, R.; ARAÚJO FILHO, J. C.; SILVA. F. B. R; LEPRUN, J. C. Os fragipãs e duripãs das depressões dos tabuleiros costeiros do nordeste brasileiro: uma proposta de evolução. Revista Brasileira de Ciência do Solo, Viçosa, v. 25, n. 4, p. 947 963, 2001.

FREELAND, R. S.; YODER, R. E.; AMMONS, J. T. Mapping shallow underground features that influence sitespecific agricultural production. Journal of Applied Geophysics, [S.1.] n. 40, p. 19-27, 1998.

GOMES, A. S. R. Estudo das mineralizações sulfetadas de Pb-Zn (Ag) da região de Nova Redenção - BA. 93f. Dissertação (Mestrado em Geologia) - Instituto de Geociências da Universidade Federal da Bahia, Salvador. Orientador: Prof. Aroldo Misi. 1998.

GREENHOUSE, J. P. Métodos geofísicos aplicados em estudos ambientais e geotécnicos. Tradução e adaptação por Clovis José. [Fortaleza : Universidade Federal do Ceará/ DEGEO]. 1998. Título original: Applications of surface geophysics to environmental investigations.

HERMAN, H. Robotic subsuface mapping using ground penetrating radar. 143f., il. Tese (Doutorado) - The Robotics Institute Carnegie Mellon University, Pitsburgh, 1997.

JOL, H. M.; SMITH, D. G.; MEYERS, R. A. Digital grounspenetrating radar (GPR): a new geophysical tool for coastal 
barrier research (exemples from the Atlantic, Gulf and Pacific coasts, U.S.A.). Journal of Coastal Research, v. 12, n. 4, p. 960-968, 1996.

JOL, H. M.; LAWTON, D. C.; SMITH, D. G. Ground penetrating radar: 2-D and 3-D subsurface imaging of a coastal barrier spit, Long Beach, WA, USA. Geomorphology, vol. 53, p. 165-181, 2003.

MISI, A.; SILVA, M. G. Chapada diamantina orientalBahia: geologia e depósitos minerais. Salvador: Superintendência de Geologia e Recursos Minerais do Estado da Bahia. 194p., il, 1994 (Série Roteiros Geológicos).

SCHROTT, L.; SASS, O. Application of field geophysics in geomorphology: Advances and limitations exemplified by case studies. Geomorphology, vol. 93, p. 55-73, 2008.
SUGUIO, K.; NOGUEIRA, A. C. R. Revisão crítica dos conhecimentos geológicos sobre a Formação (ou Grupo?) Barreiras do Néogeno e o seu possível significado como testemunho de alguns eventos geológicos mundiais. Geociências, São Paulo, v. 18, p.461-479, 1999.

TOMER, M. D.; BOLL, J.; KUNG, K-J. S.; STEENHIUS, T.; ANDERSON, J. L. Detecting illuvial lamellae in fine sand using ground-penetrating radar. Soil Science, [S.l.], v. 161, n. 2, p. 121-129, fev. 1996.

UCHA, J. M.; BOTELHO, M.; RIBEIRO, L. P.; VILAS BOAS, G. S.; SANTANA, P. S. Uso do Radar Penetrante no Solo - GPR na investigação dos solos dos tabuleiros costeiros do litoral norte do Estado da Bahia. Revista Brasileira de Ciência do Solo, Viçosa, v. 26, n. 2, p. 373-380, 2002. 